\title{
FERRAMENTAS DA EDUCAÇÃO A DISTÂNCIA: A VISÃO DO TUTOR
}

André Tenório | tenoriocederj@gmail.com

Doutorado em Física pelo Centro Brasileiro de Pesquisas Físicas (CBPF). Professor do Instituto Federal de Educação, Ciência e Tecnologia do Rio de Janeiro. Tutor a distância da Fundação CECIERJ /UFF.

Rosemeire Spedine Lopes Ferreira | rosespedine38@yahoo.com.br

Especialista em Planejamento, Implementação e Gestão da Educação a Distância. Laboratório de Novas Tecnologias. Universidade Federal Fluminense (UFF).

Michele Cristina Rodrigues de Almeida | mimeida@hotmail.com

Especialista em Planejamento, Implementação e Gestão da Educação a Distância. Laboratório de Novas Tecnologias. Universidade Federal Fluminense (UFF).

Luis Henrique Zucon | luishzu@gmail.com

Especialista em Planejamento, Implementação e Gestão da Educação a Distância. Laboratório de Novas Tecnologias. Universidade Federal Fluminense (UFF).

Thaís Tenório | tenoriocalc@gmail.com

Mestre e Doutoranda em Química pela Pontifícia Universidade Católica do Rio de Janeiro (PUC-Rio).

\section{Resumo}

A visão de um grupo de tutores sobre algumas das ferramentas da Educação a Distância foi investigada. Nove dos dez tutores de uma instituição privada de ensino superior do Estado de São Paulo responderam a questões sobre o ambiente virtual de aprendizagem, o fórum, a videoconferência, o bate-papo, o portfólio, o blog e o telefone. Segundo os pesquisados, a ação tutorial depende de um ambiente bem elaborado. O ambiente virtual de aprendizagem foi apontado como essencial à Educação a Distância, e o Moodle, citado como a plataforma mais conhecida. O bate-papo foi considerado a forma preferida de comunicação entre tutor e aluno, sucedido por fórum, telefone e videoconferência. O blog e o portfólio figuraram como instrumentos pouco explorados. O primeiro era empregado por apenas um tutor, porque para os demais o ambiente virtual de aprendizagem torná-lo-ia desnecessário. O portfólio foi descrito como um recurso de uso esporádico. A Wikipédia e o GoogleDocs não eram aproveitados pelos tutores.

\section{Palavras-chave}

Tutoria. Ferramentas da Educação a Distância. Ambiente virtual de aprendizagem. 


\section{E-learning tools: the tutor's point of view}

\section{Abstract}

The insight of a group of tutors about some of the tools of on-line education was investigated. Nine out of ten tutors of a private higher education institution in Brazilian federal state of São Paulo answered questions concerning virtual learning environment, forum, videoconferencing, chat, portfolio, blog and telephone. According to the subjects, the tutoring activity is highly dependent on a well-designed interface. The virtual learning environment was reputed essential to e-learning. Moodle was cited as the best-known interface-design platform. Chat was considered the preferred way of communication between tutor and student, followed by forum, telephone and videoconferencing. Blog and portfolio figured as underexplored instruments. Just one tutor made use of blog, since for all the others it is rendered unnecessary by the virtual learning environment. The portfolio was described as a resource of sporadic usage. Wikipedia and GoogleDocs were not used by the tutors.

\section{Keywords}

Tutoring. E-learning tools. Virtual learning environment.

\section{Introdução}

No mundo contemporâneo, a Educação a Distância (EaD) tem se destacado como uma importante modalidade de ensino. Especialmente entre indivíduos que desejam adquirir novos conhecimentos, mas necessitam de flexibilidade do momento e ou do local de estudo.

A EaD pode colaborar para o desenvolvimento educacional ao melhorar ações pedagógicas e estruturais (ARAÚJO; FREITAS, 2005). Algumas das ações pedagógicas aperfeiçoadas pela $\mathrm{EaD}$ seriam: a orien- tação da aprendizagem, a atividade docente na mediação de debates e a atuação na interatividade entre os alunos. Cita-se como exemplos de ações estruturais o emprego de ferramentas digitais ao ministrar conteúdos e a elaboração de materiais com linguagem dialógica.

A EaD apresenta novas práticas pedagógicas, metodologias de ensino e recursos didáticos (SARMET; ABRAHÃO, 2007; BARROS; SOUZA, 2009; COUTINHO; LISBOA; BOTTENTUIT Jr., 2009; DAMACENO; SANTOS, 2013).

Uma de suas contribuições é mostrar o valor das diferentes tecnologias de informação e comunicação (TIC) como ferramentas para o ensino. As TIC podem promover a difusão $e$ a divisão do conhecimento, $\mathrm{o}$ que favorece a aprendizagem colaborativa, uma característica do ensino a distância na era digital (COUTINHO; BOTTENTUIT Jr., 2007; BARROS; SOUZA, 2009; COUTINHO; LISBOA; BOTTENTUIT Jr., 2009; SPÍNDOLA; MOUSINHO, 2012; FARIAS, 2013). É de suma importância a troca de informação entre o tutor e o aluno para o sucesso de um curso a distância.

As ferramentas usadas na EaD permitem estabelecer, entre os participantes de um curso, o diálogo tão necessário a essa modalidade. Segundo Laaser (1997, p. 76), "esse diálogo deve incluir aconselhamento a respeito do que fazer, ou seja, deve servir de encorajamento para os alunos, reforço e incentivo". Essa conversa só é possível por meio de interfaces de comunicação síncronas ou assíncronas.

Autores como Gutierrez (2006), Campos, Costa e Santos (2007), Monteir, Ribeiro e Struchiner (2007), Sarmet e Abrahão (2007), Cruz (2008), Alves, Barros e Okada (2009), Barros e Souza (2009), Coutinho, Lisbôa e Bottentuit Jr. (2009), Spíndola e Mousinho (2012), Correia e Santos (2013), Comparin (2013), Farias (2013) e Rosa (2013) destacaram o emprego das TIC na EaD.

Neste trabalho, foi investigado o uso de algumas TIC por um grupo de tutores a distância. Perquiriramse como tais recursos auxiliavam na ação tutorial e na interação com os participantes dos cursos. 


\section{Metodologia}

No presente artigo, a importância de alguns meios de comunicação para o ensino a distância foi analisada. Investigaram-se a utilização $e$ as percepções de tutores sobre o ambiente virtual de aprendizagem (AVA), o fórum, a videoconferência, o bate-papo, o portfólio, o blog e o telefone. A Wikipédia, o GoogleDocs e as redes sociais não foram discutidos, pois não eram empregados na tutoria.

A pesquisa foi realizada com nove tutores de cursos de graduação a distância de uma instituição privada de ensino superior localizada no Estado de São Paulo. Um não participou do estudo por estar de licença médica. A amostra possuía boa representatividade, pois perfazia $90 \%$ da população de tutores da instituição.

O estudo teve caráter qualitativo. Os dados foram coletados em agosto de 2013, de acordo com a disponibilidade de cada tutor e mediante assinatura de concordância e consentimento livre e esclarecido para participação na pesquisa.

Os tutores responderam individualmente a um questionário de 53 perguntas aplicado pessoalmente pelos pesquisadores. O pesquisado elaborou a resposta conforme suas percepções para algumas perguntas; em outras, foram apresentadas opções e uma era escolhida de acordo com a opinião do tutor. As questões diziam respeito à formação acadêmica, à atuação na função de tutor e às diversas TIC aproveitadas no processo de ensino-aprendizagem a distância.

\section{Resultados e discussões}

3.1. Análises dos dados pessoais e profissionais dos tutores

Entre os pesquisados, sete eram do sexo feminino $(78 \%)$ e dois do masculino (22\%). A maioria, à época da coleta de dados tinha mais de 40 anos (5 indivíduos, $56 \%$ ); $22 \%$ tinham de 30 a 40 e $22 \%$ possuíam de 20 a 30 anos.

Todos os tutores possuíam nível superior, mas em áreas de conhecimento diversas, com exceção de dois graduados em Pedagogia. A maioria concluiu alguma pós-graduação lato sensu (67\%) e um, strictu sensu (11\%).

Apenas $22 \%$ fizeram um curso específico para atuar como tutor a distância, oferecido pela própria instituição onde prestavam serviços educacionais. Talvez por isso alguns questionamentos dos pesquisadores sobre as TIC usadas na EaD tenham ficado sem resposta.

No que tange à experiência profissional, a maioria atuava tanto na tutoria em modalidade semipresencial quanto na exclusivamente a distância (Tabela 1).

Tabela 1: Experiência como tutor

\begin{tabular}{c|c|c}
\hline Experiência na tutoria & Modalidade semipresencial & Modalidade a distância \\
\hline Náo atua & 1 & 2 \\
\hline Entre 1 e 5 anos & 8 & 7 \\
\hline Entre 5 e 10 anos & 0 & 0 \\
\hline Mais de 10 anos & 0 & 0 \\
\hline
\end{tabular}

A maioria dos tutores da instituição era de mulheres com mais de quarenta anos, com graduação e pós-graduação nas áreas de formação e atuantes na tutoria há menos de cinco anos.
3.2. A visão dos tutores pesquisados sobre algumas ferramentas da EaD

Os tutores foram unânimes em destacar o uso de diferentes ferramentas no planejamento e desenvolvimento dos cursos da instituição. A Tabela 2 mostra a importância de alguns recursos, segundo os pesquisados. A Tabela 3 destaca a utilização das ferramentas. 
Tabela 2: Importância atribuída a algumas ferramentas da EaD pelos tutores (em que $1^{\circ}$ é a mais importante e $7^{\circ}$ a menos importante)

\begin{tabular}{c|c|c|c|c|c|c|c}
\hline \multirow{2}{*}{ Ferramentas de EaD } & \multicolumn{7}{|c}{ Ordem de importância para os tutores } \\
\cline { 2 - 9 } & $1^{\circ}$ & $2^{\circ}$ & $3^{\circ}$ & $4^{\circ}$ & $5^{\circ}$ & $6^{\circ}$ & $7^{\circ}$ \\
\hline AVA & 8 & 0 & 0 & 0 & 0 & 0 & 0 \\
\hline Telefone & 0 & 0 & 0 & 0 & 0 & 2 & 5 \\
\hline Videoconferência & 0 & 3 & 1 & 1 & 1 & 1 & 0 \\
\hline Bate-papo & 2 & 2 & 3 & 2 & 0 & 0 & 0 \\
\hline Portfólio & 0 & 2 & 2 & 1 & 2 & 1 & 0 \\
\hline Blog & 0 & 0 & 0 & 3 & 1 & 1 & 2 \\
\hline Fórum & 0 & 1 & 2 & 1 & 3 & 1 & 0 \\
\hline
\end{tabular}

Algumas ferramentas, como a Wikipédia, o GoogleDocs e as redes sociais, contudo, não eram empregadas. A comunicação entre tutor e alunos por meio das redes sociais era desestimulada pela instituição, sob a alegação de exposição demasiada da figura do tutor e de diálogos com fins não educacionais.

De acordo com $89 \%$ dos tutores, o AVA seria o principal recurso da EaD. Ao comparar o ensino a distância $e$ o presencial, ele equivaleria à sala de aula. No AVA, tutor e alunos, mesmo separados na distância e no tempo, constroem o conhecimento interativamente.

O telefone foi o menos importante para $56 \%$, apesar de usado por $78 \%$ no desempenho de suas funções. Os tutores destacaram sua grande utilidade para dirimir situações de dúvida, o que tornaria mais dinâmico o atendimento do tutor ao aluno.
O bate-papo (ou chat), a videoconferência e o portfólio foram considerados mais valiosos para as atividades a distância que o fórum e o blog (Tabela 2). Contudo, o fórum era mais utilizado na prática tutorial que a videoconferência ou o portfólio (Tabela 3). Os chats eram empregados por $89 \%$ dos tutores e as videoconferências, por $67 \%$.

Segundo diversos autores (MARTINDALE; WILEY, 2005; BRESCIA; MILLER, 2006; COUTINHO; BOTTENTUIT Jr., 2007), o blog é uma ferramenta de grande potencial para a EaD por funcionar como um ambiente digital de acesso e disponibilização de informação que permite colaboração, discussão, intercâmbio e integração entre os usuários. Contudo, ele não era aproveitado pelos tutores (89\%), pois para eles o AVA o substituía.

Tabela 3: Utilização das ferramentas pelos tutores

\begin{tabular}{c|c|c|c}
\hline Ferramentas de EaD & Tutor utiliza a ferramenta & Tutor não utiliza a ferramenta & Não respondeu \\
\hline AVA & 8 & 0 & 1 \\
\hline Telefone & 7 & 2 & 0 \\
\hline Videoconferência & 6 & 3 & 0 \\
\hline Bate-papo & 8 & 1 & 0 \\
\hline Portfólio & 5 & 2 & 2 \\
\hline Blogs & 1 & 8 & 0 \\
\hline Fórum & 7 & 2 & 0 \\
\hline
\end{tabular}

Apesar da importância atribuída ao portfólio, apenas $56 \%$ o empregavam. Ele foi considerado essencial na finalização de um curso a distância.
Entretanto, alguns o atualizavam ao menos duas vezes no semestre. Dos $22 \%$ que não o utilizavam, metade achava que deveria. Dois pesquisados (22\%) não conseguiram 
responder às questões sobre o portfólio, o que indica a possibilidade de desconhecimento de tal ferramenta.

A essência do portfólio é sistematizar e organizar de forma intencional o conteúdo estudado. Ele possibilita a abordagem do assunto discutido de forma estratégica e serve para aprimorar novas ideias e conhecimentos. Nessa ferramenta, o aprendiz "guarda" o material de seu aprendizado e faz registros que o auxiliam a memorizar as várias etapas de um curso. Tal recurso pedagógico pode ser partilhado por tutores, professores, alunos e instituição, além de funcionar como arquivo dos materiais disponibilizados durante um curso (BRASIL, 2007).
Dois tutores $(22 \%)$ destacaram o poder do portfólio digital no auxílio à atuação tutorial ao afirmar vantagens como "enriquecer o conhecimento" e "facilitar a aprendizagem".

Quanto à frequência de utilização das ferramentas (Tabela 4), 78\% afirmaram acessar diariamente o AVA durante todo o período letivo. Os bate-papos apareceram como segunda opção dos tutores: $44 \%$ o usavam diariamente e $33 \%$ semanalmente.

As videoconferências e os fóruns eram utilizados diariamente por $22 \%$. O fórum era também usado semanalmente por $56 \%$. O blog era aproveitado diariamente na ação tutorial por $11 \%$.

Tabela 4: Frequência da utilização das ferramentas pelos tutores

\begin{tabular}{c|c|c|c|c|c|c}
\hline Ferramentas de EaD & Diaria-mente & A cada dois dias & Semanal-mente & Esporadi-camente & Não respondeu & Não utiliza \\
\hline AVA & 8 & 0 & 0 & 0 & 1 & 0 \\
\hline Videoconferência & 2 & 0 & 0 & 3 & 1 & 0 \\
\hline Bate-papo & 4 & 0 & 3 & 1 & 5 & 2 \\
\hline Portfólio & 0 & 0 & 0 & 0 & 0 & 2 \\
\hline Blog & 1 & 0 & 0 & 0 & 8 \\
\hline Fórum & 2 & 0 & 5 & & 0 \\
\hline
\end{tabular}

A Tabela 5 mostra a quantidade de tutores que empregavam cada par de ferramentas. Tal correlação permite conhecer os recursos usados em conjunto. As respostas mostraram que geralmente os tutores utilizavam duas ou mais ferramentas na complementação de uma para outra.

A maioria (78\%) usava tanto o chat quanto o fórum em suas atividades, o que exemplifica a importância desses recursos nos cursos de $\mathrm{EaD}$. A despeito de ser um recurso mais antigo, o telefone foi notado como uma das principais ferramentas do ensino a distância. Muitos (67\%) usavam-no e a videoconferência durante a prática pedagógica. Grande parte daqueles que tiravam proveito da videoconferência também usavam o bate-papo ou o fórum (44\%). Quatro dos sete tutores que usavam o fórum também empregavam a videoconferência e o portfólio (44\%).

Todos os tutores que utilizavam o portfólio digital também aproveitavam o telefone (56\%) nas atividades pertinentes aos cursos. Além disso, quatro dos cinco tutores que usavam o portfólio também empregavam o bate-papo e o fórum (44\%).

Tabela 5: Correlação do uso das ferramentas

\begin{tabular}{c|c|c|c|c|c|c|c}
\hline Ferramentas & AVA & Telefone & Videoconferência & Chat & Portfólio & Blog & Fórum \\
\hline AVA & 8 & 6 & 5 & 7 & 4 & 0 & 6 \\
\hline Telefone & 6 & 7 & 6 & 6 & 5 & 1 & 5 \\
\hline Videoconferência & 5 & 6 & 6 & 4 & 2 & 1 & 4 \\
\hline Chat & 7 & 6 & 4 & 8 & 4 & 1 & 7 \\
\hline Portfólio & 4 & 5 & 2 & 4 & 5 & 1 & 4 \\
\hline Blog & 0 & 1 & 1 & 1 & 1 & 1 & 1 \\
\hline Fórum & 6 & 5 & 4 & 7 & 4 & 1 & 7 \\
\hline
\end{tabular}


O blog era empregado por somente um tutor, o único que não usava o AVA, fato que pode tê-lo levado a destacar a relevância do blog frente a seus colegas de trabalho. Esse tutor utilizava as demais ferramentas investigadas, possuía especialização em novas tecnologias da $\mathrm{EaD}$, curso de formação para atuação como tutor e estava na instituição há aproximadamente um ano.

No contexto de um curso a distância, o blog é um espaço de divulgação da informação especializada e de interação e colaboração entre os sujeitos (COUTINHO; BOTTENTUIT Jr., 2007). Nele ocorre a integração entre o ensino de conteúdos e a comunicação por debates digitais acerca de assuntos valorizados por um grupo. Todavia, com exceção do tutor que o usava, nenhum acreditava em seu potencial para as atividades da tutoria a distância quando existia um AVA. Na visão dos pesquisados, os blogs também não figuravam como importantes, porque em geral o fórum, o e-mail e o chat eram mais utilizados.

Segundo a percepção dos tutores, o bate-papo tinha enorme utilidade durante os cursos para a interação com e entre os alunos. O fórum, a videoconferência e o telefone apareceram como recursos influentes, o que sugeriu a necessidade de haver novas, mas também velhas tecnologias para a real interação entre os sujeitos envolvidos na $\mathrm{EaD}$. O portfólio digital e o blog foram as ferramentas de menor destaque entre os tutores.

\subsection{O AVA na perspectiva dos tutores}

Nos AVAs encontram-se vários atores do processo de construção do conhecimento, e um dos principais é o tutor. Ele desempenha o papel essencial de mediar e de interagir com os alunos (BORTOLOZZO; BARROS; SOUZA, 2009; HACK, 2010). No AVA, o tutor, além de ter domínio do material de estudo, deve ser capaz de manter a interatividade entre o grupo pelas ferramentas do ambiente (SOEK; HARACEMIV, 2008).

São múltiplas as funções e as competências designadas ao tutor (BERNARDINO, 2011). Um bom tutor necessita adquirir competências como saber empregar as TIC, ter uma linguagem clara e amigável, ter ética, ter postura crítica e reflexiva, ter acessibilidade e prontidão, oferecer respostas ao aluno rapidamente, ser motivador da aprendizagem, desenvolver senso de comunidade, acolher as diferenças, ser cordial, ter empatia, ser companheiro e manter a tranquilidade (MAIA, 2002; SOUZA et al, 2004).

Entre os fatores que auxiliam a atuação do tutor ressalta-se um AVA adequadamente configurado. Um AVA bem construído tem qualidade textual e gráfica, contém suportes para a comunicação, é flexível, acessível e de fácil navegação (KLERING; SCHRÖEDER, 2011). Deve ser um espaço onde ocorre o processo de ensino-aprendizagem a distância e precisa ser capaz de promover nos alunos o sentimento de fazer parte de um grupo. Todos os pesquisados citaram a necessidade de o AVA ser bem elaborado para promover a frequência do aluno nas atividades de um curso.

O Moodle - sigla de Modular Object-Oriented Dynamic Learning Environment - é uma plataforma educacional virtual bastante empregada. Possui algumas vantagens frente a outros AVAs, como ser um software livre e gratuito, ao que se deve sua vasta utilização, além de ter interface simples e de fácil acesso e customização, em que se encontram "ferramentas de comunicação, de avaliação, de disponibilização de conteúdos, de administração e de organização" (CAMPOS; COSTA; SANTOS, 2007, p. 45).

O Moodle era a plataforma educacional mais conhecida (Tabela 6). Dois conheciam o E-Proinfo e apenas um, o Aulanet. O Moodle em geral é mais utilizado nos cursos a distância por sua facilidade de acesso e de edição (KLERING; SCHRÖEDER, 2011), além de muitas instituições terem como prática o seu uso.

A seleção e a avaliação de um AVA dependem dos objetivos de ensino institucionais e do perfil dos usuários, mas alguns itens devem sempre ser considerados: a documentação, a escalabilidade, a extensibilidade, os recursos, a usabilidade e a manutenção (CAMPOS; COSTA; SANTOS, 2007). 
Tabela 6: AVAs que os tutores conhecem

\begin{tabular}{c|c}
\hline Tipos de AVAs & Quantidade de tutores \\
\hline Teleduc & 0 \\
\hline Moodle & 8 \\
\hline E-Proinfo & 2 \\
\hline Learning Space Forum & 0 \\
\hline Webct & 0 \\
\hline Aulanet & 1 \\
\hline Outros & 0 \\
\hline Não respondeu & 1 \\
\hline
\end{tabular}

Segundo Campos, Costa e Santos (2007, p. 18), as características de um AVA podem ser assim resumidas:

- Oferecer ferramentas para disponibilizar material didático virtual para os alunos e links para outros sites na web;

- Oferecer ferramentas para avaliar o progresso e o desenvolvimento dos alunos;

- Oferecer ferramentas para administrar avaliações, testes e exercícios, mantendo os resultados armazenados;

- Oferecer ferramentas para ajudar os professores a administrar aulas e notas;
- Facilitar a edição/criação das páginas na web;

- Oferecer ferramentas de cadastro de usuários e de portfólios individuais;

- Oferecer grande diversidade de ferramentas de comunicação.

A Figura 1 exemplifica formas de um AVA auxiliar as atividades da tutoria a distância, segundo os pesquisados. Todos o indicaram como um espaço onde se compartilha a aprendizagem. Partilhar informações e saberes num ambiente coletivo ajudaria na atuação tutorial por dinamizar a aprendizagem.

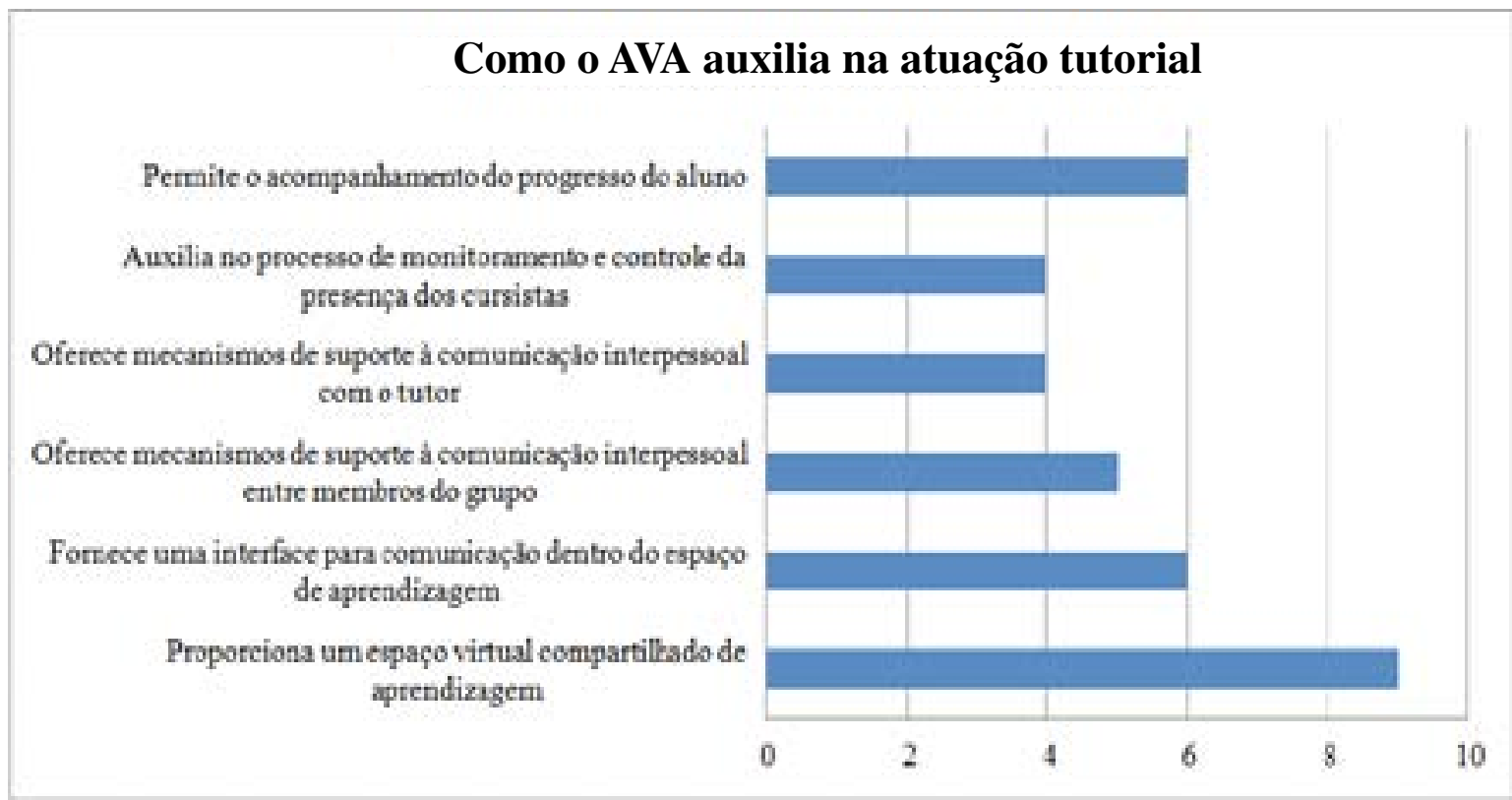

Figura 1: Opinião dos tutores sobre como o AVA auxilia na atuação tutorial 
A maioria (67\%) mencionou recursos do AVA como permitir o acompanhamento do aluno e fornecer interface para comunicação dentro do espaço de aprendizagem. Monitorar o progresso do estudante é fundamental para o processo de ensino-aprendizagem a distância, pois ao identificar dificuldades é possível empregar outras práticas pedagógicas ou metodologias de ensino para a construção do conhecimento. Ter interfaces para a comunicação no AVA também ajuda o tutor, afinal a EaD depende do diálogo virtual.

Grande parte destacou os mecanismos de suporte à comunicação com o tutor $(44 \%)$ e entre os cursistas (56\%). Em um AVA há a transmissão de conteúdos e a interação dos envolvidos em um curso a distância. Nele podem se encontrar vários recursos e ferramentas tecnológicas que auxiliarão o tutor na mediação do processo de ensino-aprendizagem para todos os participantes. As ferramentas existentes nos AVAs podem ser de dois tipos: síncronas (interação em tempo real) ou assíncronas (interação em momentos diferentes). O intuito é proporcionar aos alunos uma aprendizagem significativa, autônoma, colaborativa e interativa por meio de uma atuação tutorial de qualidade presente em todos os momentos.

De modo geral, os tutores descreveram o AVA como um ambiente em que se compartilha a aprendizagem, que deve estar bem configurado para a participação constante dos alunos. Embora o AVA seja um recurso essencial da $\mathrm{EaD}$, poucos conheciam outras plataformas além do Moodle.

\subsection{A videoconferência na atuação tutorial}

A videoconferência é um recurso que "traz" os cursistas para um mesmo local virtual. Ela objetiva o debate em determinado momento, com ou sem a presença do tutor, numa troca de informações (e dúvidas) realizada em um ambiente on line, em que perguntas e respostas surgem de acordo com a necessidade de cada um (GUTIERREZ, 2006).

Uma das características necessárias ao uso da videoconferência desvia um pouco da "liberdade" proporcionada pela $\mathrm{EaD}$. Nas reuniões, ela requer a presença de todos os participantes em determinado dia e horário, mas cada qual em seu equipamento (preservação parcial da liberdade).

$\mathrm{Na}$ instituição, a videoconferência assumia posição de destaque. Quase $45 \%$ dos tutores a reconheciam como uma das três principais ferramentas da EaD e a caracterizavam como completa.

Acredita-se que sua utilização só não seja maior porque ainda esbarra no obstáculo de maior difusão de sinal de banda larga, imprescindível para a transmissão de vídeo.

Ao comparar as videoconferências aos batepapos virtuais, nota-se como diferença fundamental a presença de imagem e voz dos conferencistas nas primeiras, o que simularia melhor uma conversa real.

Os custos envolvidos seriam outra diferença. É preciso disponibilizar equipamentos e acesso à internet de banda larga para os cursistas que, por ventura, não os tenham em suas residências. Oferecer aos alunos salas de informática adequadas e com máquinas em número suficiente se reflete diretamente nos custos institucionais, pois ainda há a necessidade de ter permanentemente assistência técnica e manutenção.

Alguns poderiam ver a existência de um laboratório de informática na instituição como um rompimento da liberdade de escolha do local de estudo fomentada pela $\mathrm{EaD}$, pois isso caracterizaria o deslocamento do aluno. Todavia, os laboratórios são necessários como opção para os que não podem acessar a plataforma de outros locais.

A maioria dos tutores $(67 \%)$ acreditava que a videoconferência ajudava na prática pedagógica. Na Tabela 7 foram transcritas as opiniões sobre o potencial da videoconferência para a atuação tutorial.

Os tutores I, III e V descreveram como essa ferramenta ajudava na explicação de dúvidas ou conteúdos mais difíceis. O tutor III destacou seu dinamismo. Os tutores II, IV e VI ressaltaram a importância da interação entre os participantes por meio da troca de informações em uma videoconferência.

Os tutores VIII e IX viam-na como um recurso desnecessário, pelo fato de o tutor a distância ficar na instituição ao exercer suas atividades, de modo a atender pessoalmente o aluno interessado. 
Tabela 7: Transcrições das opiniões dos tutores sobre o auxílio da videoconferência na prática pedagógica

\begin{tabular}{c|l}
\hline Tutor & \multicolumn{1}{|c}{ Transcrição das respostas sobre como a videoconferência auxiliaria a atuação tutorial } \\
\hline I & Nelas, as aulas são ao vivo. Então, os alunos podem fazer perguntas e igualmente são respondidas as questões apresentadas. \\
\hline II & Há troca de experiência entre alunos e professores. \\
\hline III & Ela favorece questionar e obter as respostas instantaneamente. \\
\hline IV & Com ela, a troca de experiências e novas técnicas são construídas entre os envolvidos. \\
\hline V & A videoconferência possui grande capacidade de esclarecer conteúdos em que os alunos têm dificuldades específicas. \\
\hline VI & Ela permite ao acadêmico assistir aulas e, ao mesmo tempo, interagir. \\
\hline VII & Não respondeu. \\
\hline VIII & A videoconferência não auxilia, porque a tutoria também pode ser presencial. \\
\hline IX & A videoconferência não ajuda. Já existe a teleaula e os tutores presentes na instituição. \\
\hline
\end{tabular}

Na percepção da maioria dos pesquisados, a videoconferência, apesar de demandar mais recursos financeiros e diminuir a liberdade do momento de estudo, ajuda na atuação tutorial. Afinal, promove a interação e facilita a explicação de tópicos de difícil compreensão.

\subsection{O bate-papo virtual na atuação tutorial}

O chat ou bate-papo virtual é uma ferramenta que permite uma maior aproximação entre os participantes de um curso. Ele permite a comunicação de maneira rápida e traz o aluno, mesmo que virtualmente, à presença do tutor.

A principal diferença entre o bate-papo e a videoconferência diz respeito ao formato de comunicação, unicamente por mensagens escritas no primeiro. Outra diferença seria a facilidade de cada participante registrar a conversa no formato de texto, para consulta ou estudo em momento posterior.

$\mathrm{Na}$ instituição, o bate-papo era o principal recurso de comunicação entre tutor e aluno. Quase $90 \%$ dos tutores o empregavam e $78 \%$ o reputavam umas das três principais ferramentas na estrutura de um curso a distância.

Apesar do uso do bate-papo, somente 44\% conseguiram responder como o recurso os auxiliava na prática pedagógica. O tutor III ressaltou a sua capacidade em ajudar na troca de informações. Os tutores I, VII e VIII citaram a facilidade de solucionar dúvidas ao empregá-lo.
Quando numa mesma "sala" virtual, os participantes trocavam informações e experiências, no intuito de aumentar o conhecimento por meio da aprendizagem colaborativa. Ele ainda podia ser empregado para discutir dúvidas ou encontrar respostas a questionamentos comuns a um grupo.

Diante da possibilidade de os alunos solicitarem a abertura de um bate-papo para o esclarecimento de dúvidas, aproximadamente $56 \%$ dos tutores não só afirmaram ser possível como opinaram a favor de tal prática.

Perante o emprego difundido do bate-papo na instituição, foi necessário discutir os sistemas de controle e de avaliação da participação dos alunos.

Por volta de $30 \%$ dos tutores indicaram a necessidade de a instituição estabelecer o controle da participação dos alunos em cada bate-papo virtual. Alguns mencionaram até a alternativa de a administração da instituição utilizar tais dados como mecanismo de controle de participação, de modo a conhecer as taxas de abandono das disciplinas.

Havia também a necessidade de estabelecer critérios para doutrinar a atribuição de pontuação à participação nos bate-papos. Notou-se a opção a cargo do tutor em aproveitar ou não o recurso para fins avaliativos.

Apenas 33\% empregavam algum tipo de critério de avaliação. O tutor III mencionou ser uma boa escolha atribuir às participações no bate-papo uma pontuação extra para a composição da nota final do aluno, o que estimularia a participação e maior contato com o curso a distância. 
$\mathrm{Na}$ visão dos tutores, o bate-papo era fundamental para a comunicação tutor-aluno. Seu emprego ajudava na troca de informações e no debate de dúvidas. Entretanto, a instituição não o utilizava como recurso para o controle da participação ou para a avaliação dos alunos.

\subsection{O telefone na atuação tutorial}

Apesar de todos os tutores atuarem na mesma instituição, nem todos $(22 \%)$ dispunham do telefone para a comunicação com o aluno.

Todavia, todos achavam necessário ele estar disponível para o contato com o cursista. Na conversa por telefone, o fato de ouvir uma voz empática pode transmitir sensação de bem-estar e até de confiança. Isso ajudaria o aluno a discutir questões mal interpretadas de imediato ou resolver alguma emergência.
Dos $78 \%$ que podiam usá-lo, alguns o empregavam pouco. Segundo os pesquisados, a iniciativa dos telefonemas ocorria tanto da parte do tutor quanto do aluno.

Contudo, somente $56 \%$ confirmaram a gratuidade da ligação. $\mathrm{O}$ fato de o telefone não poder ser usado sem custos limitava o seu emprego. Afinal, muitos alunos da EaD não residem no mesmo município da instituição, o que torna a ligação mais onerosa.

Grande parte $(44 \%)$ estimou o tempo médio do atendimento para cada aluno em até 10 minutos. Somente $11 \%$ realizavam mais de dez atendimentos telefônicos por jornada diária de tutoria.

A maioria dos tutores destacou o telefone como um aliado na prática pedagógica, pois ele ajudaria a discutir dúvidas rapidamente (Tabela 8).

Os tutores I e IX comentaram a preferência dos alunos por utilizar a internet em relação ao telefone. Entretanto, eles não dispunham da ferramenta para comunicação com o aluno.

Tabela 8: Transcrições das opiniões dos tutores sobre o auxílio do telefone na prática pedagógica

\begin{tabular}{c|l}
\hline Tutor & \multicolumn{1}{|c}{ Transcrição das respostas sobre como o telefone auxiliaria a atuação tutorial } \\
\hline I & $\begin{array}{l}\text { Com o sistema de priorizar o uso da internet, os alunos também preferem esse tipo de contato ou, pessoalmente, na sala de aula. } \\
\text { O telefone é pouco usado. }\end{array}$ \\
\hline II & O telefone serve para mediar as dúvidas de imediato. \\
\hline III & O telefone é um meio de comunicação imediato, de modo que posso resolver o assunto em questão rapidamente. \\
\hline IV & Pelo telefone é possível mediar/resolver às dúvidas imediatamente. \\
\hline V & O contato telefônico permite esclarecer algumas dúvidas com maior rapidez e clareza do que o contato através de mensagens e fóruns. \\
\hline VI & O telefone serve para dirimir as dúvidas. \\
\hline VII & O uso do telefone é apenas para emergências ou casos específicos. É importante que o aluno receba as instruções por outros meios. \\
\hline VIII & O telefone é para reclamações urgentes. \\
\hline IX & Em geral, a maioria dos alunos prefere usar a internet. \\
\hline
\end{tabular}

Segundo os tutores, o telefone seria um recurso necessário à EaD. Seu uso deveria ser esporádico e limitado, empregado mormente em situações urgentes ou se o aluno não entendeu as instruções dadas por outros meios de comunicação.

\section{Conclusões}

Com a expansão do ensino a distância, é fundamental estabelecer o diálogo na relação tutor-aluno. Essa troca contínua de experiências e de informações é possibilitada pelas novas TIC, que permitem a construção do conhecimento de forma abrangente e eficaz. As comunidades virtuais, mantidas por meio 
do uso de ferramentas provenientes das TIC, permitiriam a comunicação e a interação entre os pares.

Ao considerar um curso a distância, Silva (2000, p. 62) ressalta a ideia de que "o desafio do professor é mudar sua comunicação em salas de aula ou na educação", além de sugerir que todo tutor-professor necessita conhecer e saber manipular as ferramentas disponíveis. Isso o auxiliaria a manter a participação e uma comunicação eficaz, o que beneficiaria o processo de ensino-aprendizagem (SILVA, 2000; CORREIA; SANTOS, 2013; FARIAS, 2013).

A EaD destaca-se justamente pela modalidade de ensino apresentada, ou seja, o aluno é atraído pela vantagem de poder escolher a hora e o local de estudo. Atualmente, contudo, o sucesso de um curso a distância depende em parte das TIC (CORREIA; SANTOS, 2013).

Campos, Costa e Santos (2007, p. 13) delimitam as ferramentas utilizadas na $\mathrm{EaD}$ como "equipamentos que captam os movimentos dos usuários e respondem em tempo real, favorecendo uma interação mais realista e gerando sensações próximas àquelas experimentadas em ambientes reais similares".

A pesquisa mostrou que, geralmente, os tutores empregavam dois ou mais recursos de forma complementar.

O bate-papo foi a ferramenta mais lembrada ou usada, seguido do fórum, da videoconferência e do telefone.

Em termos gerais, tanto o bate-papo quanto a videoconferência possuíam boa aceitação pelos cursistas. O telefone era uma ferramenta empregada contínua e brevemente na comunicação entre cursistas e tutores. Ele era mais usado para tirar dúvidas ou solucionar questões emergenciais, não como pilar na construção do conhecimento.

Do ponto de vista pedagógico, o blog e o portfólio digital seriam importantes aliados da EaD por apresentarem características potenciais para a disseminação de informações. Todavia, a pesquisa constatou a não utilização do blog e o uso pouco frequente do portfólio.

Há duas possibilidades para isso. Uma seria o pouco valor atribuído pela instituição a tais ferramen- tas. Outra seria a falta de desenvoltura no emprego delas por pouco ou nenhum conhecimento ou treinamento em TIC, o que prejudicaria sua utilização. Isso poderia ocorrer por muitos tutores $(78 \%)$ não possuírem um curso de treinamento ou capacitação em tutoria a distância.

Além disso, conforme mencionado pelos pesquisados, o blog acabaria sendo uma ferramenta pouco aproveitada por existir um AVA institucional com diversos recursos.

O maior uso do portfólio digital em comparação ao blog ocorreria por, no passado, algumas instituições exigirem um portfólio manuscrito no desenvolvimento dos cursos.

O estudo evidenciou a extrema importância do AVA para a aprendizagem a distância. Os AVAs permitem inúmeras possibilidades de interação no decorrer de um curso, ao reunir num mesmo espaço virtual uma gama de informações e ferramentas, o que ajudaria na compreensão de novos conhecimentos $e$ no desenvolvimento da autonomia pelos alunos. Tais ambientes ajudariam os usuários a não se sentirem desprovidos de uma sala de aula física.

Segundo a percepção dos tutores, o AVA seria um dos principais meios de transmitir os conteúdos a serem estudados em um curso a distância. Sem ele seria bem mais difícil disseminar o conhecimento. Todos foram unânimes em dizer que utilizavam ou conheciam algum tipo de AVA.

Um AVA necessita da disponibilidade de várias ferramentas e recursos, além de pessoal qualificado. Os tutores viam um AVA bem construído como um estímulo à troca de informações.

Segundo os pesquisados, o AVA seria o principal recurso da $\mathrm{EaD}$, e as ferramentas mais usadas na comunicação tutor-cursista seriam o bate-papo e o fórum.

De maneira geral, os tutores conheciam e utilizavam a maioria das ferramentas analisadas, mas algumas ainda eram negligenciadas, principalmente devido a recomendações da instituição ou pouca habilidade em manipulá-las. 
Uma perspectiva para estudos seria analisar as opiniões de alunos acerca das ferramentas da $\mathrm{EaD} e$ de como cada uma delas ajudaria na aprendizagem. Investigar outras instituições também poderia ampliar a compreensão sobre a aplicabilidade das TIC no ensino a distância.
A pesquisa visou revelar as percepções de tutores sobre as ferramentas da $\mathrm{EaD}$. Conhecer como e com qual frequência são empregadas pode ajudar a tornar a prática pedagógica da tutoria a distância mais eficiente e melhorar a experiência de aprendizado dos cursistas.

\section{Referências}

ALVES, L.; BARROS, D.; OKADA, A. (org.). Moodle: estratégias pedagógicas e estudos de caso. Salvador: Eduneb, 2009.

ARAÚJO, B.; FREITAS, K. S. Educação a distância no contexto brasileiro: algumas experiências da UFBA. Salvador: Editora UFBA, 2005.

BARROS, J.; SOUZA, P. O fórum de discussão em $\mathrm{EaD}$ e a promoção da aprendizagem colaborativa: as estratégias interacionais utilizadas pelo tutor. Anais eletrônicos... 2009. Disponível em: < http://www.ufpe.br/ nehte/hipertexto2009/anais/m-o/o-forum-de-discussao-em-ead.pdf > . Acesso em: 8 fev. 2014.

BERNARDINO, H. S. A tutoria na EaD: os papéis, as competências e a relevância do tutor. Revista Científica de Educação a Distância, Santos, v. 2, n. 4, jul. 2011. Disponível em: < http://revistapaideia.unimesvirtual. com.br/index.php?journal $=$ paideia\&page $=$ article\&op=viewFile\&path[] $=166 \&$ path []$=171>$. Acesso em: 8 fev. 2014.

BORTOLOZZO, A. R. S.; BARROS, G. C.; MOURA, L. M. C. Quem é e o que faz um professor-tutor. In: CONGRESSO NACIONAL DE EDUCAÇÃO EDUCERE, 9, 2009, Paraná. Anais eletrônicos... Paraná: PUC-Paraná, 2009. Disponível em: <http://www.portugues.seed.pr.gov.br/arquivos/File/ead/ana.pdf> . Acesso em: 8 fev. 2014.

BRASIL. Ministério da Educação. Secretaria de Educação a Distância. Referenciais de qualidade para educação superior a distância. Brasília, 2007. $31 \mathrm{f}$.

BRESCIA, W.; MILLER, M. What's it worth? the perceived benefits of instructional blogging. Electronic Journal for the Integration of Technology in Education, Idaho, v. 5, p. 44-52, 2006.

CAMPOS, F. C. A.; COSTA, R. M.; SANTOS, N. Fundamentos da educação a distância, mídias e ambientes virtuais. Juiz de Fora: Editar, 2007. $48 \mathrm{f}$.

COMPARIN, E. R. A. Concepções e tendências do trabalho docente na educação a distância: um estudo de caso. 2013. 220 f. Tese (Doutorado em Educação). Universidade Federal do Paraná, Curitiba, 2013. CORREIA, R. L.; SANTOS, J. G. A importância da tecnologia da informação e comunicação (TIC) na educação a distância (EaD) do Ensino Superior (IES). Revista Aprendizagem em EAD, Taguatinga, v. 2, p. 1-16, nov. 2013.

COUTINHO, C. P.; BOTTENTUIT Jr., J. B. Blog e Wiki: os futuros professores e as ferramentas da Web 2.0. Revista do Simpósio Internacional de Informática Educativa SIIE, Porto, n. 14-16, p. 199-204, nov. 2007.

COUTINHO, C. P.; LISBÔA. E. S.; BOTTENTUIT Jr., J. B. Avaliação online através das ferramentas da web 2.0. Revista científica de educação a distância, Santos, v. 2, n. 1, jun. 2009. Disponível em: <http:// revistapaideia. unimesvirtual.com.br/index.php?journal $=$ paideia\&page $=$ article\&op $=$ view\&path []$=79 \& p a$ th[] $=45$ >. Acesso em: 8 fev. 2014. 
CRUZ, D. M. A construção do professor midiático: o docente comunicador na educação a distância por videoconferência. Cadernos de Educação, Pelotas, v. 30, p. 201-214, jan./jun. 2008.

DAMACENO, D. V.; SANTOS, R. M. R. Objetos de aprendizagem no contexto escolar. Revista de Educação, Ciência e Tecnologia, Canoas, v. 2, n. 2, p. 1-21, 2013.

FARIAS, S. C. Os benefícios das tecnologias da informação e comunicação (TIC) no processo de educação a distância (EaD). Revista Digital de Biblioteconomia e Ciência da Informação, Campinas, v. 11, n. 3, p. 15-29, set./dez. 2013.

GUTIERREZ, O. L. B. A educação a distância, o uso de novas tecnologias e a ênfase no audiovisual. Revista Global Manager, Rio Grande do Sul, ano 7, n. 11, p. 77-87, dez. 2006.

HACK, J. R. Comunicação dialógica na educação superior a distância: a importância do papel do tutor. Signo pensam, Bogotá, v. 29, n. 56, p. 114-123, jan./jun. 2010. Disponível em: <http://www.scielo.org.co/scielo. php?pid=S0120-48232010000100007\&script=sci_arttext $>$. Acesso em: 8 fev. 2014.

LAASER, W. (org.). Manual de criação e elaboração de materiais para a educação a distância. Brasília: Editora da UnB, 1997.

MAIA, C. Guia brasileiro de educação a distância. São Paulo: Esfera, 2002.

MARTINDALE, T.; WILEY, D. Using weblogs in scholarship and teaching. Techtrends, v. 49, n. 2, p. 55-61, 2005.

MONTEIR, D. M.; RIBEIRO, V. M. B.; STRUCHINER, M. As tecnologias da informação e da comunicação nas práticas educativas: espaços de interação? Estudo de um fórum virtual. Educação \& Sociedade, Campinas, v. 28, n. 101, p. 1.435-1.454, set./dez. 2007.

ROSA, S. S. A influência das TDIC na (re)configuração de modelos de EaD tradicionais para educação online. Novas Tecnologias na Educação, Rio Grande do Sul, v. 11, n. 3, p. 1-15, dez. 2013.

SARMET, M. M.; ABRAHÃO, J. I. O tutor em educação a distância: análise ergonômica das interfaces mediadoras. Educação em Revista, Belo Horizonte, n. 46, p. 109-141, dez. 2007.

SILVA, M. Sala de aula interativa. Rio de Janeiro: Quartet, 2000.

SOEK, A. M.; HARACEMIV, S. M. C. O professor/tutor e as relações de ensino-aprendizagem na educação a distância. Revista Brasileira de Aprendizagem Aberta e a Distância, São Paulo, v. 7, n. 1, p 1-11, 2008. Disponível em: <http://www.abed.org.br/revistacientifica/Revista_PDF_Doc/2008/ARTIGO_07_RBAAD_2008_ ENSAIO.pdf $>$. Acesso em: 8 fev. 2014.

SOUZA, C. A.; SPANHOL, F. J.; LIMAS, J. C. O.; CASSOL, M. P. Tutoria como espaço de interação em educação a distância. Revista Diálogo Educacional, Paraná, v. 4, n. 13, set./dez. 2004. p. 1-11. Disponível em: <http:// www2.pucpr.br/reol/index.php/DIALOGO?dd1=762\&dd99=view >. Acesso em: 8 fev. 2014.

SPÍNDOLA, M.; MOUSINHO, S. H. Cederj: um caminho na direção da educação inclusiva. EAD em foco, Rio de Janeiro, v. 118, n. 2, p. 36-46, nov. 2012. 